\title{
Effects of oral orbifloxacin on fecal coliforms in healthy cats: a pilot study
}

\author{
Kazuki HARADA ${ }^{1) *}$, Atsushi SASAKI ${ }^{1)}$ and Takae SHIMIZU ${ }^{1)}$ \\ 1)Department of Veterinary Internal Medicine, Tottori University, 4-101 Minami, Koyama-Cho, Tottori-Shi, Tottori 680-8553, Japan
}

(Received 6 July 2015/Accepted 13 August 2015/Published online in J-STAGE 27 August 2015)

ABSTRACT. The study objective was to determine the effect of oral orbifloxacin (ORB) on antimicrobial susceptibility and composition of fecal coliforms in cats. Nine cats were randomized to two groups administered a daily oral dose of 2.5 and $5.0 \mathrm{mg}$ ORB/ $\mathrm{kg}$ for $7 \mathrm{days}$ and a control group (three cats per group). Coliforms were isolated from stool samples and were tested for susceptibilities to ORB and 5 other drugs. ORB concentration in feces was measured using high-performance liquid chromatography (HPLC). The coliforms were undetectable after 2 days of ORB administration, and their number increased in most cats after termination of the administration. Furthermore, only isolates of Escherichia coli were detected in all cats before administration, and those of Citrobacter freundii were detected after termination of the administration. $E$. coli isolates exhibited high ORB susceptibility [Minimum inhibitory concentration (MIC), $\leq 0.125 \mu \mathrm{g} / \mathrm{m} l$ ] or relatively low susceptibility (MIC, $1-2 \mu \mathrm{g} / \mathrm{m} l$ ) with a single gyrA mutation. C. freundii isolates largely exhibited intermediate ORB susceptibility (MIC, $4 \mu \mathrm{g} / \mathrm{m} l$ ), in addition to resistance to ampicillin and cefazolin, and harbored qnrB, but not a gyrA mutation. HPLC revealed that the peaks of mean concentration were 61.3 and $141.0 \mu \mathrm{g} / \mathrm{g}$ in groups receiving $2.5 \mathrm{and} 5.0 \mathrm{mg} / \mathrm{kg}$, respectively. Our findings suggest that oral ORB may alter the total counts and composition of fecal coliform, but is unlikely to yield highly fluoroquinolone-resistant mutants of $E$. coli and $C$. freundii in cats, possibly because of the high drug concentration in feces. KEY WORDS: antimicrobial resistance, fecal coliforms, feline, orbifloxacin

doi: 10.1292/jvms.15-0407; J. Vet. Med. Sci. 78(1): 83-89, 2016

Orbifloxacin (ORB) is a synthetic antimicrobial agent of the fluoroquinolone (FQ) class and has a wide range of antibacterial activity and high bioavailability [14]. In companion animal medicine, ORB is approved for treatment of several bacterial infections, such as urinary tract infection and skin infection, and has been widely used in many countries [1,32].

The development of FQ-resistant bacteria increases the risk of FQ treatment failure in companion animals. In addition to an effect on animal health, the prevalence of FQ-resistant bacteria may have important consequences for human public health, if the resistant isolates or resistance determinants are transmitted to humans from their pets $[15,20]$. Understanding the development of FQ resistance is important not only from a veterinary perspective but also from a global public health perspective. FQ resistance is mainly acquired by the modification of target enzymes, i.e. DNA gyrase and topoisomerase IV; however, it may also involve the acquisition of plasmid-mediated quinolone resistance (PMQR) determinants [13]. Such acquisition of FQ resistance is closely associated with selective pressure resulting from the use of FQ drugs [25].

Coliforms, including Escherichia coli, are representative commensal bacteria in the gut of animals and can act as an indicator of antimicrobial resistance $[11,30]$. Notably,

\footnotetext{
*Correspondence to: Harada, K.,Department of Veterinary Internal Medicine, Tottori University, 4-101 Minami, Koyama-Cho, Tottori-Shi, Tottori 680-8553, Japan.

e-mail:k-harada@muses.tottori-u.ac.jp

(C)2016 The Japanese Society of Veterinary Science

This is an open-access article distributed under the terms of the Creative Commons Attribution Non-Commercial No Derivatives (by-nc-nd) License $<$ http://creativecommons.org/licenses/by-nc-nd/3.0/>.
}

most FQ drugs after administration migrate to the gut and urine $[21,24]$; therefore, the gut flora, including coliforms, is likely exposed to FQs in animals administered with the drugs. To assess the effect of FQ use on the fecal or gut flora, experiments with FQ administration have been previously conducted on various animals, such as pigs [4], chickens [22] and dogs [29]. However, the similar experiments have not yet been performed on cats, a representative species of companion animals.

In this study, we assessed antimicrobial susceptibility, bacterial species and the number of fecal coliforms in cats treated with two specific doses of ORB, as well as untreated cats. We also determined several genetic mechanisms of FQ resistance in coliform bacteria isolated from treated and untreated cats.

\section{MATERIALS AND METHODS}

Study design and enrolled cats: Nine domestic short-haired cats living at a research facility were enrolled; mean age was $6.11 \pm 1.71$ years, and body weight was $3.51 \pm 0.42 \mathrm{~kg}$. All cats were selected from a research colony maintained under standard laboratory conditions at the Tottori University. None of the cats had received antimicrobials for at least six months prior to the study, and all cats were deemed healthy based on a physical examination and a hematological examination. The cats were randomized into three groups (groups A, B and C) of three cats each. The cats in groups A and $B$ received a daily oral dose of 5 and $2.5 \mathrm{mg} \mathrm{ORB} / \mathrm{kg}$ (DS Pharma Animal Health, Osaka, Japan), respectively, for 7 consecutive days, as approved dosages in Japan. The cats in group $\mathrm{C}$ served as a control. Further, the cats were fed commercial dry cat food and received no medication other 
than ORB during the study. All cats were housed in separate cages located in one room, and direct contact among the cats was prevented during the study. Only when administered with ORB, the cats were separately led out of each cage. Authors contacting with the cats wore a new disposable glove in each case. This study was approved by Tottori University Animal Use Committee (approval number, 13-T-29).

Isolation and identification of fecal coliforms: Stool samples were collected from each of the 9 cats on days 1,3 , $5,7,9,11,13,15$ and 17 . On day 1 , the sample was obtained before drug administration. Serial 10-fold dilutions were then prepared from $1 \mathrm{~g}$ of each stool sample in $0.1 \%$ peptone water. Once the appropriate dilution was prepared, $0.1 \mathrm{~m} l$ was plated onto eosin methylene blue (EMB) agar (Nissui Pharmaceutical Co., Ltd., Tokyo, Japan) containing either no drugs or ORB at the concentration of $2 \mu \mathrm{g} / \mathrm{ml}$, which was defined as the concentration of intermediate susceptibility in to the Clinical and Laboratory Standards Institute Guidelines [8]. On EMB agar, coliform colonies develop a metallic luster, other gram-negative bacteria appear colorless, and gram-positive bacteria cannot grow. The inoculated plates were incubated at $35^{\circ} \mathrm{C}$ for $24 \mathrm{hr}$, and the number of coliform bacteria was enumerated as colony-forming units (CFU)/g of feces. A maximum of 10 coliform colonies per cat per sampling were picked up and subjected to identification of bacterial species. Isolates were confirmed to be E. coli by gram staining, the typical colony shape on deoxycholate hydrogen sulphide lactose agar (Nissui Pharmaceutical Co., Ltd.) and detection of the uid gene by PCR [3]. When isolates were not identified as E. coli, they were identified using the API 20E Kit (SYSMEX bioMérieux Co., Ltd., Tokyo, Japan). After bacterial identification, the isolates were stored in $10 \%$ skim milk at $-80^{\circ} \mathrm{C}$ for antimicrobial susceptibility testing and genetic analysis. The remaining stool samples were frozen at $-80^{\circ} \mathrm{C}$ until high performance liquid chromatography (HPLC) analysis.

Antimicrobial susceptibility testing: Susceptibility testing against ORB was conducted using the agar dilution method, according to the Clinical and Laboratory Standards Institute Guidelines [9]. In addition, susceptibilities to ampicillin (AMP), cefazolin (CEZ), tetracycline (TET), chloramphenicol (CHL), kanamycin (KAN) and trimethoprim/sulfamethoxazole (SXT) were determined using the disk diffusion method [9]. The results were interpreted as per criteria of the CLSI guidelines [8]. E. coli ATCC 25922 was used as the quality control strain. In CEZ-resistant isolates, AmpC $\beta$-lactamase and extended-spectrum $\beta$-lactamase (ESBL) were phenotypically screened using cefoxitin disks $(30 \mu \mathrm{g} /$ disk) and cefotaxime ( $3 \mu \mathrm{g})$, respectively; the results were considered positive, if the inhibition zone diameters were $\leq 14$ and $\leq 27 \mathrm{~mm}$, respectively [10, 28]. Further, AmpCpositive isolates were defined as derepressed AmpC mutants or inducible AmpC producers, as previously described [18].

Analysis of the mechanism of $F Q$ resistance: Isolates with an ORB MIC of $\geq 1 \mu \mathrm{g} / \mathrm{m} l$ were assessed for the presence of mutations of the quinolone resistance-determining region (QRDR) and PMQR determinants.

The QRDR of the gyrA gene was amplified by PCR with previously described primers [12]. The resulting amplicons were bidirectionally sequenced using the same primers. The QRDR of the parC gene was also amplified and sequenced using previously described primers [12], when QRDR mutations were detected in $g y r A$.

PMQR genes were detected using multiplex PCR as previously reported [7]. Any ambiguous PCR results were clarified with repeat assays. PCR products were then randomly selected and bidirectionally sequenced with the same primers for confirmation.

Enterobacterial repetitive intergenic consensus sequencebased PCR: Enterobacterial repetitive intergenic consensus sequence-based PCR (ERIC-PCR) was carried out to investigate epidemiologic relationship among the PMQR-positive isolates. The procedure was slightly modified from the previous studies [27, 31]. Briefly, the PCR reaction was set up in a $20 \mu \mathrm{l}$ reaction volume containing $2 \mu \mathrm{l}$ of a $10 \times$ ExTaq buffer, $1 \mathrm{U}$ of ExTaq DNA polymerase (Takara Bio Inc., Otsu, Japan), $0.25 \mathrm{mM}$ each of the dNTPs, 10-30 $\mathrm{ng}$ of bacterial DNA and 20 pmol of each primer (i.e. ERIC1R and ERIC2). DNA amplifications were performed with an initial denaturation $\left(7 \mathrm{~min}\right.$ at $\left.94^{\circ} \mathrm{C}\right)$ followed by 30 cycles of denaturation $\left(1 \mathrm{~min}\right.$ at $\left.94^{\circ} \mathrm{C}\right)$, annealing $\left(1 \mathrm{~min}\right.$ at $\left.52^{\circ} \mathrm{C}\right)$ and extension $\left(8 \mathrm{~min}\right.$ at $\left.65^{\circ} \mathrm{C}\right)$ with a final extension $\left(15 \mathrm{~min}\right.$ at $\left.65^{\circ} \mathrm{C}\right)$.

Measurement of ORB concentration in feces: Stool samples were obtained from cats in groups A and B on days 1, 3, 5, 7 and 9 and from cats in group $\mathrm{C}$ on days 1 and 9 . The concentration of ORB in feces was determined at the Research Institute for Animal Science in Biochemistry and Toxicology (Sagamihara, Japan). In brief, ORB in stool samples was extracted with acetonitrile containing $1 \%$ formic acid and purified via liquid-liquid partition, salting-out and a mini-column (Oasis MAX $^{\circledR}$, Nihon Waters K.K., Tokyo, Japan). ORB was analyzed using an HPLC system (Shimadzu Corporation, Kyoto, Japan) equipped with a binary pump, an autosampler, a column heater and a fluorescence detector. For separation, Supelcosil Abzplus (Sigma-Aldrich Co., LLC, Tokyo, Japan) was concurrently used with LiChroCART 4-4 LiChrosher 100 RP-18 Guard Column (Merck, Tokyo, Japan). Limitation of quantitation was determined as $0.1 \mu \mathrm{g} / \mathrm{g}$. The quality control was carried out by analyzing stool samples together with samples of known concentrations (i.e. 0.2 and $2 \mu \mathrm{g} / \mathrm{g}$ ) every time.

Statistical analysis: Standard one-way analysis of variance with the Tukey-Kramer multiple comparison test was used to compare the mean age and body weight of the enrolled cats, and mean CFU/g of stool samples among groups $\mathrm{A}, \mathrm{B}$ and $\mathrm{C}$. The Mann-Whitney $U$ test was used to compare mean concentrations of ORB in feces between groups A and B. Fisher's exact test was used to compare rates of antimicrobial resistance between groups and periods (i.e. before and after treatment). A $P$ value of $<0.05$ was considered as statistically significant in all analyses.

\section{RESULTS}

Enrolled cats: There were no differences in age or body weight among the three groups $(P>0.05)$. No adverse effects 


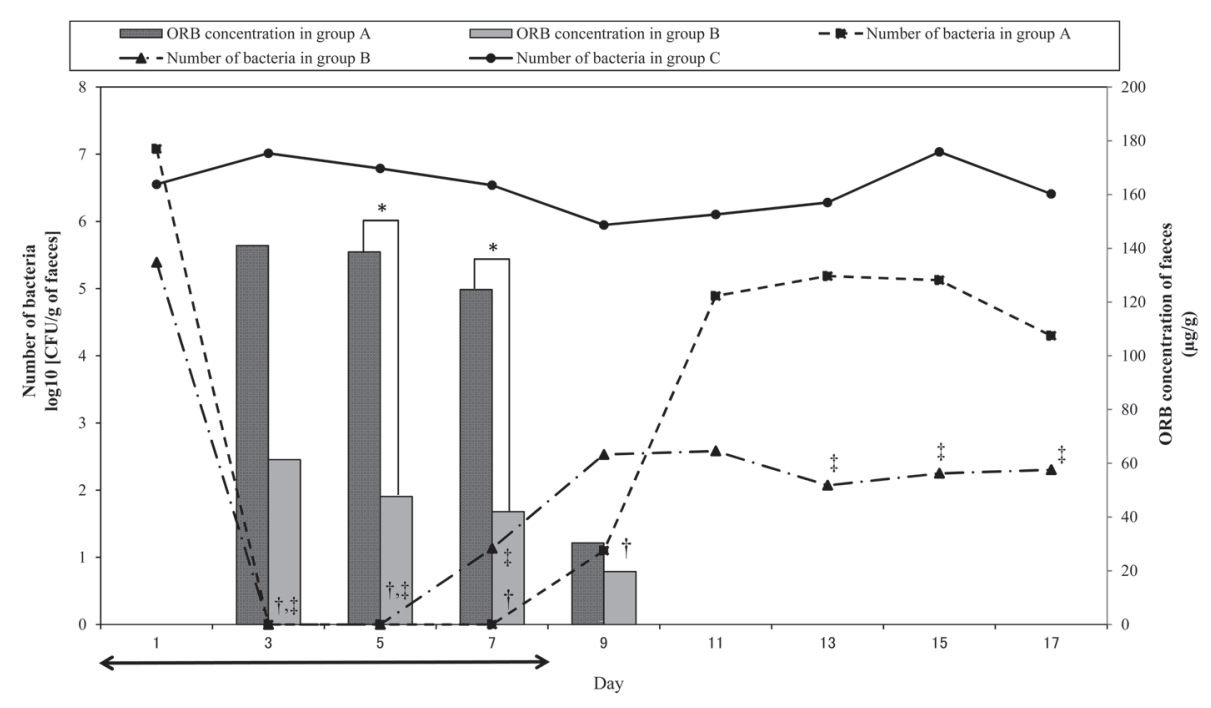

Fig. 1. The means of the total number of coliforms and ORB concentration in the feces of cats in groups $\mathrm{A}, \mathrm{B}$ and $\mathrm{C}$ during the test schedule. In groups $\mathrm{A}$ and $\mathrm{B}, \mathrm{ORB}$ was administered orally daily at a dose of 5.0 and $2.5 \mathrm{mg} / \mathrm{kg}$, respectively, on days 1-7 $(\leftrightarrow)$. See Supplemental Figs. 1 and 2 for the total number of coliforms and ORB concentration, respectively, in each cat. ${ }^{\dagger}$ Significantly lower number of coliforms in groups $\mathrm{A}$ and $\mathrm{B}$, respectively, compared with group $\mathrm{C}(P<0.05)$. *There were significant differences between groups $\mathrm{A}$ and $\mathrm{B}(P<0.05)$.

of the drug were noted in any cat.

Total number of coliforms in cats: The total number of coliforms during the test schedule is shown in Fig. 1 and Supplemental Fig. 1. According to the one-way analysis of variance and the Tukey-Kramer multiple comparison test, pre-treatment coliform counts in groups A, B and C were not significantly different $(7.08 \pm 0.53,5.39 \pm 0.72$ and $6.55 \pm$ 1.11 , respectively).

In groups $\mathrm{A}$ and $\mathrm{B}$, within 3 days of ORB administration, the number of fecal coliforms decreased rapidly and continued to be significantly lower than that of group $\mathrm{C}$ $(P<0.05)$, until day 9 or 7 , respectively. After cessation of ORB treatment, coliform counts in the cats of groups A and B mostly reached detectable levels by days 9 (cat 3) and 11 (cats 1 and 2) and by days 7 (cat 5) and 9 (cat 6), respectively. There were no significant differences in coliform counts between groups $\mathrm{A}$ and $\mathrm{C}$ from day $11(P>0.05)$. On the other hand, significant differences were found in coliform counts between groups $\mathrm{B}$ and $\mathrm{C}(P<0.05)$ on days 13,15 and 17 , because of extremely low counts of coliform in cats 4 and 6. Significant differences between groups A and B were not seen during the study period $(P>0.05)$. No remarkable fluctuations were observed in coliform counts in the cats of group $\mathrm{C}$ during the study period.

Rates of antimicrobial resistance of coliforms in cats: By antimicrobial susceptibility testing, ORB resistance was not detected in groups A and B before the treatment. After the treatment, ORB resistance was found in group B $(6.0 \%)$; however, there was no significant difference in the resistance rates before and after the treatment $(P>0.05)$. On the other hand, ORB resistance was not detected in group A after the treatment.
Compared to before treatment, rates of AMP resistance were significantly high in groups $\mathrm{A}$ and $\mathrm{B}$ after the treatment ( $0 \%$ vs. $26.2 \%$ and $0 \%$ vs. $76.2 \%$, respectively, $P<0.01$ ); rates of CEZ resistance were also significantly high in these groups after the treatment ( $0 \%$ vs. $26.2 \%$ and $0 \%$ vs. $76.2 \%$, respectively, $P<0.01)$. There were significant differences in rates of resistance to the two drugs between groups $\mathrm{A}$ and $\mathrm{B}$ after the treatment $(P<0.01)$.

In group $\mathrm{C}$, resistance to any antimicrobials tested was not detected during test period.

Changes in the composition of the bacterial population of fecal coliforms: Coliform species are shown in Table 1. On day 1 , all isolates from cats in groups A, B and C were identified as $E$. coli.

After ORB treatment, the isolates of Citrobacter freundii were detected in all cats in groups A and B. In group A, $C$. freundii isolates were detected on days 11, 13, 15 and/or 17 , whereas in group B, the bacteria were detected on days 7, 9, 11,13 and/or 17. Furthermore, E. coli isolates were detected alone or along with $C$. freundii isolates in all cats except cat 4 (from group B), in whom coliforms were not detected until day 15 after treatment initiation, and only $C$. freundii isolates were detected on day 17 . In group $\mathrm{C}$, all isolates were identified as E. coli.

Using EMB agar containing ORB, coliforms were detected with $10^{3.08} \mathrm{CFU} / \mathrm{g}$ in cat 3 (from group A) on day 15 and with $10^{3.28} \mathrm{CFU} / \mathrm{g}$ in cat 4 (from group B) on day 17 after treatment initiation; these isolates were identified as $E$. coli and $C$. freundii (cat 3 ) and $C$. freundii alone (cat 4). No growth of coliforms was detected in the other cats by using ORB-containing EMB agar.

Coliform bacteria other than $E$. coli or $C$. freundii were 
Table 1. Bacterial species of coliforms from stool samples obtained from cats during the test schedule

\begin{tabular}{ccccccccccc}
\hline \multirow{2}{*}{ Group $^{\text {a) }}$} & \multirow{2}{*}{} & Cat & \multicolumn{10}{c}{ Date of sampling (No. of isolates) } \\
\cline { 2 - 10 } & & 1 & 3 & 5 & 7 & 9 & 11 & 13 & 15 & 17 \\
\hline \multirow{3}{*}{$\mathrm{A}$} & 1 & $\mathrm{Ec}$ & - & - & - & - & $\mathrm{Cf}$ & $\mathrm{Ec}$ & $\mathrm{Ec}$ & $\mathrm{Ec}$ \\
& 2 & $\mathrm{Ec}$ & - & - & - & - & $\mathrm{Ec}$ & $\mathrm{Ec} / \mathrm{Cf}$ & $\mathrm{Cf}$ & $\mathrm{Ec}$ \\
& 3 & $\mathrm{Ec}$ & - & - & - & $\mathrm{Ec}$ & $\mathrm{Ec}$ & $\mathrm{Ec}$ & $\mathrm{Ec}^{\mathrm{c}} / \mathrm{Cf}^{\mathrm{c}}$ & $\mathrm{Ec} / \mathrm{Cf}$ \\
\hline \multirow{3}{*}{$\mathrm{B}$} & 4 & $\mathrm{Ec}$ & - & - & - & - & - & - & - & $\mathrm{Cf}^{\mathrm{c})}$ \\
& 5 & $\mathrm{Ec}$ & - & - & $\mathrm{Cf}$ & $\mathrm{Cf}$ & $\mathrm{Ec} / \mathrm{Cf}$ & $\mathrm{Ec}$ & $\mathrm{Ec}$ & $\mathrm{Cf}$ \\
& 6 & $\mathrm{Ec}$ & - & - & - & $\mathrm{Cf}$ & $\mathrm{Cf}$ & $\mathrm{Cf}$ & $\mathrm{Ec}$ & - \\
\hline & 7 & $\mathrm{Ec}$ & $\mathrm{Ec}$ & $\mathrm{Ec}$ & $\mathrm{Ec}$ & $\mathrm{Ec}$ & $\mathrm{Ec}$ & $\mathrm{Ec}$ & $\mathrm{Ec}$ & $\mathrm{Ec}$ \\
$\mathrm{C}$ & 8 & $\mathrm{Ec}$ & $\mathrm{Ec}$ & $\mathrm{Ec}$ & $\mathrm{Ec}$ & $\mathrm{Ec}$ & $\mathrm{Ec}$ & $\mathrm{Ec}$ & $\mathrm{Ec}$ & $\mathrm{Ec}$ \\
& 9 & $\mathrm{Ec}$ & $\mathrm{Ec}$ & $\mathrm{Ec}$ & $\mathrm{Ec}$ & $\mathrm{Ec}$ & $\mathrm{Ec}$ & $\mathrm{Ec}$ & $\mathrm{Ec}$ & $\mathrm{Ec}$ \\
\hline
\end{tabular}

a) Groups $\mathrm{A}$ and B were treated with 5 and $2.5 \mathrm{mg} \mathrm{ORB} / \mathrm{kg}$, respectively. Group C was control (untreated). b) ORB was administered orally during days 1-7. Ec: Escherichia coli; Cf: Citrobacter freundii. c) The isolates were also detected using EMB agar containing ORB $(2 \mu \mathrm{g} / \mathrm{m} l)$ and exhibited low (MIC: $1 \mu \mathrm{g} / \mathrm{m} l$ ) or intermediate susceptibility to ORB (MIC: $2-4 \mu \mathrm{g} / \mathrm{m} l$ ).

Table 2. Antimicrobial susceptibility and FQ resistance mechanisms of coliforms from cats before and after ORB administration

\begin{tabular}{|c|c|c|c|c|c|c|c|c|c|}
\hline \multirow[b]{2}{*}{ Group ${ }^{\text {a) }}$} & \multirow[b]{2}{*}{ Cat } & \multirow[b]{2}{*}{ Period } & \multicolumn{2}{|c|}{ Isolates } & \multirow{2}{*}{$\begin{array}{l}\text { MIC range of } \\
\text { orbifloxacin } \\
(\mu \mathrm{g} / \mathrm{m} l)\end{array}$} & \multicolumn{2}{|c|}{ QRDR mutation } & \multirow[b]{2}{*}{ PMQR } & \multirow{2}{*}{$\begin{array}{l}\text { Susceptibility to other } \\
\text { antimicrobials }\end{array}$} \\
\hline & & & Species $^{\mathrm{b})}$ & $n$ & & GyrA & ParC & & \\
\hline \multirow{12}{*}{ A } & \multirow{3}{*}{1} & Pre-treatment & Ec & 10 & 0.063 & & & & Susceptible \\
\hline & & \multirow{2}{*}{ Post-treatment } & Ec & 30 & $0.063-0.125$ & & & & Susceptible \\
\hline & & & $\mathrm{Cf}$ & 10 & 4 & None & & $q n r B$ & AMP CEZ \\
\hline & \multirow{3}{*}{2} & Pre-treatment & Ec & 10 & $0.063-0.125$ & & & & Susceptible \\
\hline & & \multirow{2}{*}{ Post-treatment } & Ec & 22 & $0.031-0.125$ & & & & Susceptible \\
\hline & & & $\mathrm{Cf}$ & 18 & 4 & None & & $q n r B$ & AMP CEZ \\
\hline & \multirow{6}{*}{3} & Pre-treatment & $\mathrm{Ec}$ & 10 & 0.063 & & & & Susceptible \\
\hline & & \multirow{5}{*}{ Post-treatment } & \multirow{2}{*}{ Ec } & 5 & $0.031-0.063$ & & & & Susceptible \\
\hline & & & & 39 & 1 & S83L $\mathrm{L}^{\mathrm{d})}$ & None & None & Susceptible \\
\hline & & & $\mathrm{Cf}$ & 6 & 4 & None & & $q n r B$ & AMP CEZ \\
\hline & & & $\mathrm{Ec}^{\mathrm{c})}$ & 4 & $1-2$ & $\mathrm{~S} 83 \mathrm{~L}^{\mathrm{d})}$ & None & None & Susceptible \\
\hline & & & $\mathrm{Cf}^{\mathrm{c})}$ & 6 & 4 & None & & $q n r B$ & AMP CEZ \\
\hline \multirow{10}{*}{ B } & \multirow{3}{*}{4} & Pre-treatment & Ec & 10 & $0.063-0.125$ & & & & Susceptible \\
\hline & & \multirow{2}{*}{ Post-treatment } & $\mathrm{Cf}$ & 10 & 4 & None & & $q n r B$ & AMP CEZ \\
\hline & & & $\mathrm{Cf}^{\mathrm{c})}$ & 10 & 4 & None & & $q n r B$ & AMP CEZ \\
\hline & \multirow{3}{*}{5} & Pre-treatment & Ec & 10 & 0.063 & & & & Susceptible \\
\hline & & \multirow{2}{*}{ Post-treatment } & Ec & 9 & $0.063-0.25$ & & & & Susceptible \\
\hline & & & $\mathrm{Cf}$ & 25 & 4 & None & & $q n r B$ & AMP CEZ \\
\hline & \multirow{4}{*}{6} & Pre-treatment & Ec & 10 & 0.063 & & & & Susceptible \\
\hline & & \multirow{3}{*}{ Post-treatment } & Ec & 10 & $0.063-0.125$ & & & & Susceptible \\
\hline & & & \multirow{2}{*}{$\mathrm{Cf}$} & 25 & 4 & None & & $q n r B$ & AMP CEZ \\
\hline & & & & 5 & 8 & None & & $q n r B$ & AMP CEZ \\
\hline \multirow{3}{*}{$\mathrm{C}$} & 7 & All & Ec & 89 & $0.063-0.125$ & & & & Susceptible \\
\hline & 8 & All & Ec & 90 & $0.063-0.125$ & & & & Susceptible \\
\hline & 9 & All & $\mathrm{Ec}$ & 87 & $0.063-0.125$ & & & & Susceptible \\
\hline
\end{tabular}

a) Groups $\mathrm{A}$ and B were treated with 5 and $2.5 \mathrm{mg} \mathrm{ORB} / \mathrm{kg}$, respectively. Group C was control (untreated). b) Ec: Escherichia coli, Cf: Citrobacter freundii. c) The isolates were detected using EMB agar containing ORB (2 $\mu \mathrm{g} / \mathrm{m} l)$. d) S83L: codon position 83 , serine-to-leucine mutation. 
not identified during the test schedule.

Resistance mechanisms in E. coli and C. freundii: As for ORB resistance, E. coli isolates were highly susceptible (MIC, $0.031-0.25 \mu \mathrm{g} / \mathrm{ml}$ ) in cats 1 and 2 (from group A), and 4, 5 and 6 (from group B) not only before treatment but also after treatment (Table 2). On the other hand, isolates with low or intermediate susceptibility (MIC, $1-2 \mu \mathrm{g} / \mathrm{m} l$ ) were predominantly detected in cat 3 (from group 1) after treatment, and these isolates had a single QRDR mutation in gyrA at codon position 83 (serine to leucine: S83L). In group C, all E. coli isolates were highly susceptible to ORB (MIC, $0.063-0.125 \mu \mathrm{g} / \mathrm{ml}$ ) during the test schedule. All $C$. freundii isolates from cats $1-5$ demonstrated intermediate susceptibility (MIC, $4 \mu \mathrm{g} / \mathrm{m} l$ ), whereas the resistant isolates (MIC, $8 \mu \mathrm{g} / \mathrm{m} l$ ) were barely detectable only in cat 6 on days 9, 11 and 13. According to PCR and sequencing results, none of the $C$. freundii isolates had QRDR mutations in gyrA, but carried $q n r B$, one of the PMQR genes.

All $E$. coli isolates were susceptible to the 5 tested antimicrobials, whereas all $C$. freundii isolates were resistant to AMP and CEZ. All C. freundii isolates were phenotypically confirmed to be inducible AmpC producers, but not ESBL producers.

Genetic relationship between $C$. freundii isolates from cats: Four C. freundii isolates each from cats 1-6 (from groups A and B) were selected and subjected to ERIC-PCR. As the result, all of these isolates had the identical banding pattern (data not shown).

ORB concentration in feces of ORB-treated cats: The changes in ORB concentration in feces are shown in Fig. 1 and Supplemental Fig. 2. On day 1 before treatment initiation, ORB was not detected in stool samples from any cat. ORB was detected in cats of groups A and B between days 3 and 9 after treatment initiation. Highest concentration of ORB was determined in cats 2 and 6 of groups A and B, respectively, between days 3 and 7. The peaks of mean concentration in groups A and B were observed on day 3 (141.0 and $61.3 \mu \mathrm{g} / \mathrm{g}$, respectively). On days 5 and 7 , significantly higher concentrations of ORB were detected in group A than in group $\mathrm{B}(P<0.05)$. On the other hand, ORB was not detected in all of cats in group $\mathrm{C}$ on days 1 and 9.

\section{DISCUSSION}

To the best of our knowledge, this is the first study to evaluate the effects of oral FQ on the fecal flora of cats. We have demonstrated that the counts of coliform bacteria significantly decreased during and after the period for administration of ORB. A similar reduction in the number of coliforms was reported in dogs treated with enrofloxacin [29]. Thus, these data indicate that FQ administration reduces the number of coliforms in the fecal flora of cats and dogs. As for the composition of the bacterial population of the fecal coliform bacteria, only $E$. coli was detected in all cats on day 1, whereas isolates of $C$. freundii and $E$. coli were detected as a dominant species of all cats in groups $\mathrm{A}$ and $\mathrm{B}$ after cessation of ORB treatment. Few reports have addressed the effect of antimicrobial treatment on the composition of the bacterial population of fecal or gut flora in animals. Johnson et al. [17] detected the emergence of Streptococcus spp. and Corynebacterium spp. in cats after the administration of metronidazole. Lawrence et al. [19] confirmed the increase in the number of enterococcal cells in dogs after the administration of cefovecin. Although there were several differences in test condition between studies, our and their results suggest that administration of antimicrobials can cause increase, in addition to decrease, of specific bacterial species of fecal or gut flora, which may be explained by microbial substitution.

Pharmacokinetics of ORB has not yet been evaluated in animals treated with different doses of this antibiotic. In this study, we found clear differences in ORB concentrations in feces between the two doses $(5.0$ and $2.5 \mathrm{mg} / \mathrm{kg}$ ). This dose-dependent kinetics of ORB should be considered when administering this drug. Moreover, our results reveal remarkably high concentrations of ORB in feces of cats receiving either the high-dose or low-dose treatment. Thus, ORB is likely to be mostly excreted into the feces after oral administration: a notion supported by a previous study [21], revealing that a higher concentration of ORB is present in bile acid than in serum of cats after ORB treatment. These pharmacokinetic properties of the drug may be responsible for the significant reduction of fecal coliforms in cats after treatment.

Our study showed some variations in the numbers of coliforms and ORB concentrations in feces between cats administered with the drug, suggesting that effect of ORB treatment on fecal coliforms and pharmacokinetics of the drug may vary by individual. Such interindividual variations should be taken into account when administering the drug for cats.

Susceptibility testing revealed that no ORB-resistant $E$. coli appeared because all isolates failed to develop more than one QRDR mutation: the necessary condition for the acquisition of FQ resistance [12]. Our results strongly contradict the study by Aly et al. [2], wherein all fecal E. coli isolates exhibit high-level resistance to enrofloxacin after treatment of dogs with the drug. In general, the concept of a mutant selection window has considerable implications for the acquisition of FQ resistance, and antimicrobials at concentrations beyond the mutant prevention concentration (MPC) can prevent the development of FQ-resistant mutants [5]. In our study, the fecal ORB concentration in cats treated with the doses of 2.5 and $5.0 \mathrm{mg} / \mathrm{kg}$ far exceeds the MPC value of $E$. coli $(0.5-32 \mu \mathrm{g} / \mathrm{m} l)$; this result has been confirmed by another study [26]. These findings suggest that oral ORB poses a low risk of selection of highly FQ-resistant mutants among fecal $E$. coli isolates in cats because of high gut levels.

Compared with $E$. coli isolates, $C$. freundii isolates show higher ORB MIC values. Such low susceptibilities to FQs may give a competitive advantage to $C$. freundii when administered with ORB. Most strains of $C$. freundii maintained intermediate sensitivity to ORB. Among the tested PMQR genes, $q n r B$ was detected in all $C$. freundii isolates. This finding can be explained by a study by Jacoby et al. [16], 
revealing that chromosomal $q n r B$ is prevalent in $C$. freundii isolates. On the other hand, no QRDR mutations of $g y r A$, the basis of the FQ resistance mechanism [23], were identified in C. freundii isolates. Cesaro et al. [6] reported that QRDR mutations can be more effectively suppressed in $q n r$-positive $E$. coil strains than in qnr-negative E. coli strains; this property of $q n r$ may elucidate our present results, namely that $q n r B$-positive $C$. freundii isolates fail to acquire strong ORB resistance. It should be considered that gut flora of cats can act as a reservoir of $q n r$-positive bacteria, which are possibly selected as a result of FQ use. In coliform-positive samples after ORB treatment, $q n r$-positive $C$. freundii isolates were detected more frequently in group B (8 of 11 samples) than in group A (5 of 13 samples). This finding implies that low-dose treatment of ORB might facilitate the selection of $q n r$-positive bacteria, compared with high-dose treatment. However, to clarify this point, further large-scale studies would be needed.

As for susceptibilities to the antimicrobials other than FQs, all E. coli isolates exhibited susceptibility to all the tested antimicrobials both before and after ORB treatment. As a result, multidrug-resistant $E$. coli isolates, which were reported in dogs after enrofloxacin treatment [2], were not detected in the present study. On the other hand, all C. freundii isolates exhibited resistance to AMP and CEZ by the production of AmpC, but not ESBLs. This finding resulted in the significant increase of resistance rates to AMP and CEZ in isolates of $E$. coli and $C$. freundii after ORB treatment. Similarly, the high prevalence of ampC in this bacterial species was previously found in human isolates in a study by Kanamori et al. [18]. Our study suggests that FQ use poses a risk of coselection of AmpC-producing $C$. freundii isolates in feces of cats.

ERIC-PCR revealed that $C$. freundii isolates, which were $q n r B$-positive and AmpC-producing, from cats 1-6 (from groups A and B) were clonal or genetically identical. This result indicates that $C$. freundii isolates spread clonally in the cats; however, the cause of the clonal spread could not be identified. One hypothesis is cross-contamination between the cats during the study, despite deliberate efforts to prevent this. A similar phenomenon was reported previously [19]. Another is that ORB treatment might select $C$. freundii isolates that had spread horizontally among enrolled cats before the study. In either case, more aggressive and effective measures to prevent any transfer of bacteria would be needed for future studies.

There were several study limitations. Firstly, this study was carried out as a pilot study by using a small number of cats, and thus, the present results might be somewhat biased. Secondly, the effect of ORB treatment remains to be clarified in cats with clinical signs or household cats, because we used healthy experimental cats in research settings. Furthermore, this study covered only coliform bacteria. Fecal or gut flora in cats is composed of a variety of aerobic and anaerobic bacteria [17], in addition to coliform bacteria. Therefore, this study could not entirely clarify an effect of ORB treatment on fecal flora of cats.

Nevertheless, we have described the effects of ORB ad- ministration on fecal coliforms in healthy cats. We revealed alterations in bacterial composition, e.g. selection of $q n r B-$ and AmpC-positive $C$. freundii isolates, in addition to a decrease in the total number of coliforms. Moreover, we could not detect strongly FQ-resistant mutants among isolates of E. coli and C. freundii. Further studies using household cats with and without clinical signs are required to assess clinical and public health implications of the effects of FQ use on the fecal flora of cats.

ACKNOWLEDGMENTS. The authors would like to thank Ms. Emiko Shimoda for her technical assistance. This study was supported by a grant from DS Pharma Animal Health Co., Ltd., Japan. The sponsor of the study had no role in the study design, conduct of the study, data collection, data interpretation or preparation of the manuscript.

\section{REFERENCES}

1. Albarellos, G. A. and Landoni, M. F. 2009. Current concepts on the use of antimicrobials in cats. Vet. J. 180: 304-316. [Medline] [CrossRef]

2. Aly, S. A., Debavalya, N., Suh, S. J., Oryazabal, O. A. and Boothe, D. M. 2012. Molecular mechanism of antimicrobial resistance in fecal Escherichia coli of healthy dogs after enrofloxacin or amoxicillin administration. Can. J. Microbiol. 58: 1288-1294. [Medline] [CrossRef]

3. Bej, A. K., Dicesare, J. L., Haff, L. and Atlas, R. M. 1991. Detection of Escherichia coli and Shigella spp. in water by using the polymerase chain reaction and gene probes for uid. Appl. Environ. Microbiol. 57: 1013-1017. [Medline]

4. Belloc, C., Lam, D. N., Pellerin, J. L., Beaudeau, F. and Laval, A. 2005. Effect of quinolone treatment on selection and persistence of quinolone-resistant Escherichia coli in swine fecal flora. $J$. Appl. Microbiol. 99: 954-959. [Medline] [CrossRef]

5. Blondeau, J. M. 2009. New concepts in antimicrobial susceptibility testing: the mutant prevention concentration and mutant selection window approach. Vet. Dermatol. 20: 383-396. [Medline] [CrossRef]

6. Cesaro, A., Bettoni, R. R., Lascols, C., Mérens, A., Soussy, C. J. and Cambau, E. 2008. Low selection of topoisomerase mutants from strains of Escherichia coli harbouring plasmid-borne $q n r$ genes. J. Antimicrob. Chemother. 61: 1007-1015. [Medline] [CrossRef]

7. Ciesielczuk, H., Hornsey, M., Choi, V., Woodford, N. and Wareham, D. W. 2013. Development and evalution of a multiplex PCR for eight plasmid-mediated quinolone-resistance determinants. J. Med. Microbiol. 62: 1823-1827. [Medline] [CrossRef]

8. Clinical and Laboratory Standards Institute. 2013. Performance Standards for Antimicrobial Disk and Dilution Susceptibility Tests for Bacteria Isolated From Animals. Second Informational Supplement. CLSI document VET01-S2, Wayne.

9. Clinical and Laboratory Standards Institute. 2013. Performance Standards for Antimicrobial Disk and Dilution Susceptibility Tests for Bacteria Isolated From Animals. Approved StandardFourth Edition. CLSI document VET01-A4, Wayne.

10. Clinical and Laboratory Standards Institute. 2013. Performance Standards for Antimicrobial Susceptibility Testing; Twntieth Informational Supplement. CLSI document M100-S20, Wayne.

11. De Graef, E. M., Decostere, A., Devriese, L. A. and Haesebrouck, F. 2004. Antibiotic resistance among fecal indicator bacteria from healthy individually owned and kennel dogs. Microb. 
Drug Resist. 10: 65-69. [Medline] [CrossRef]

12. Everett, M. J., Jin, Y. F., Ricci, V. and Piddock, L. J. V. 1996. Contributions of individual mechanisms to fluoroquinolone resistance in 36 Escherichia coli strains isolated from humans and animals. Antimicrob. Agents Chemother. 40: 2380-2386. [Medline]

13. Fàbrega, A., Madurga, C., Giralt, E. and Vila, J. 2009. Mechanism of action of and resistance to quinolones. Microb. Biotechnol. 2: 40-61. [Medline] [CrossRef]

14. Gebru, E., Lee, J. S., Chang, Z. Q., Hwang, M. H., Cheng, H. and Park, S. C. 2009. Integration of pharmacokinetic and pharmacodynamic indices of orbifoxacin in beagle dogs after a single intravenous and intramuscular administration. Antimicrob. Agents Chemother. 53: 3024-3029. [Medline] [CrossRef]

15. Guardabassi, L., Schwarz, S. and Lloyd, D. H. 2004. Pet animals as reservoirs of antimicrobial-resistant bacteria. J. Antimicrob. Chemother. 54: 321-332. [Medline] [CrossRef]

16. Jacoby, G. A., Griffin, C. M. and Hooper, D. C. 2011. Citrobacter spp. as a source of $q n r B$ alleles. Antimicrob. Agents Chemother. 55: 4979-4984. [Medline] [CrossRef]

17. Johnston, K. L., Lamport, A. I., Ballèvre, O. P. and Batt, R. M. 2000. Effects of oral administration of metronidazole on small intestinal bacteria and nutrients of cats. Am. J. Vet. Res. 61: 1106-1112. [Medline] [CrossRef]

18. Kanamori, H., Yano, H., Hirakata, Y., Endo, S., Arai, K., Ogawa, M., Shimojima, M., Aoyagi, T., Hatta, M., Yamada, M., Nishimaki, K., Kitagawa, M., Kunishima, H. and Kaku, M. 2011. High prevalence of extended-spectrum $\beta$-lactamase and $q n r$ determinants in Citrobacter species from Japan: dissemination of CTX-M-2. J. Antimicrob. Chemother. 66: 2255-2262. [Medline] [CrossRef]

19. Lawrence, M., KuKanich, K., Kukanich, B., Heinrich, E., Coetzee, J. F., Grauer, G. and Narayanan, S. 2013. Effect of cefovecin on the fecal flora of healthy dogs. Vet. J. 198: 259-266. [Medline] [CrossRef]

20. Lloyd, D. H. 2007. Reservoirs of antimicrobial resistance in pet animals. Clin. Infect. Dis. 45 Suppl 2: S148-S152. [Medline] [CrossRef]

21. Matsumoto, S., Takahashi, M., Yoshida, M., Komatsu, T., Kitadai, Y., Horii, Y. and Katae, H. 1997. Absorption, distribution and excretion of orbifloxacin in dogs and cats. Jpn. J. Vet. Med. Assoc. 50: 470-474. [CrossRef]

22. Miranda, J. M., Vázquez, B. I., Fente, C. A., Barros-Velázquez, J., Cepeda, A. and Franco, C. M. 2008. Evolution of resistance in poultry intestinal Escherichia coli during three commonly used antimicrobial therapeutic treatments in poultry. Poult. Sci. 87: 1643-1648. [Medline] [CrossRef]

23. Navia, M. M., Ruiz, J., Ribera, A., de Anta, M. T. and Vila, J. 1999. Analysis of the mechanisms of quinolone resistance in clinical isolates of Citrobacter frendii. J. Antimicrob. Chemother. 44: 743-748. [Medline] [CrossRef]

24. Papich, M. G. and Riviere, J. E. 2009. Fluoroquinolone antimicrobial drugs. pp. 983-1011. In: Veterinary Pharmacology and Therapeutics, 9th ed. (Riviere, J. E. and Papich, M. G. eds.), John Wiley and Sons, Ames.

25. Piddock, L. J. 1999. Mechanisms of fluoroquinolone resistance: an update 1994-1998. Drugs 58 Suppl. 2: 11-18. [Medline] [CrossRef]

26. Shimizu, T., Harada, K. and Kataoka, Y. 2013. Mutant prevention concentration of orbifloxacin: comparison between Escherichia coli, Pseudomonas aeruginosa, and Staphylococcus pseudintermedius of canine origin. Acta Vet. Scand. 55: 37. [Medline] [CrossRef]

27. Stalder, G. L., Loncaric, I. and Walzer, C. 2014. Diversity of enterobacteria including $\beta$-lactamase producing isolates associated with the Spanish slug (Arion vulgaris). Sci. Total Environ. 479-480: 11-16. [Medline] [CrossRef]

28. Thomson, K. S. 2010. Extended-spectrum $\beta$-lactamases, AmpC, and carbapenemase issues. J. Clin. Microbiol. 48: 1019-1025. [Medline] [CrossRef]

29. Trott, D. J., Filippich, L. J., Bensink, J. C., Downs, M. T., McKenzie, S. E., Townsend, K. M., Moss, S. M. and Chin, J. J. C. 2004. Canine model for investigating the impact of oral enrofloxacin on commensal coliforms and colonization with multidrug-resistant Escherichia coli. J. Med. Microbiol. 53: 439-443. [Medline] [CrossRef]

30. van den Bogaard, A. E. and Stobberingh, E. E. 2000. Epidemiology of resistance to antibiotics. Links between animals and humans. Int. J. Antimicrob. Agents 14: 327-335. [Medline] [CrossRef]

31. Versalovic, J., Koueth, T. and Lupski, J. R. 1991. Distribution of repetitive DNA sequences in eubacteria and application to fingerprinting of bacterial genomes. Nucleic Acids Res. 19: 6823-6831. [Medline] [CrossRef]

32. Walker, R. D. 2000. The use of fluoroquinolones for companion animal antimicrobial therapy. Aust. Vet. J. 78: 84-90. [Medline] [CrossRef] 